\title{
sciendo
}

\section{EFFECT OF DIETARY SODIUM ACETATE ON SKIN MUCUS IMMUNE PARAMETERS AND EXPRESSION OF GENE RELATED TO GROWTH, IMMUNITY AND ANTIOXIDANT SYSTEM IN COMMON CARP (CYPRINUS CARPIO) INTESTINE*}

\author{
Roghieh Safari ${ }^{1}$, Seyed Hossein Hoseinifar ${ }^{1}$, Maryam Dadar ${ }^{2}$, Shabnam Nejadmoghaddam ${ }^{1}$, \\ Hien Van Doan ${ }^{3,4 \bullet}$
}

\author{
'Department of Fisheries, Faculty of Fisheries and Environmental Sciences, \\ Gorgan University of Agricultural Sciences and Natural Resources, Gorgan, Iran \\ ${ }^{2}$ Razi Vaccine and Serum Research Institute, Agricultural Research, \\ Education and Extension Organization (AREEO), Karaj, Iran \\ ${ }^{3}$ Department of Animal and Aquatic Sciences, Faculty of Agriculture, Chiang Mai University, \\ Chiang Mai 50200, Thailand \\ ${ }^{4}$ Science and Technology Research Institute, Chiang Mai University, 239 Huay Keaw Rd., Suthep, \\ Muang, Chiang Mai 50200, Thailand \\ •Corresponding author: hien.d@cmu.ac.th
}

\begin{abstract}
The present study investigated the possible effects of including salt of short chain fatty acid, sodium acetate (SA), on skin mucus immune parameters and immune, antioxidant and growth-related genes expression in common carp. There is little data available about the effective role of SA on immune, antioxidant and growth related genes expression as well as skin mucus immune parameters. The aim of this study was to analyse the effect of SA intake on these factors using common carp (Cyprinus carpio) as model organism. Two hundred and forty healthy common carps (mean weight $=15 \pm 0.9 \mathrm{~g}$ ) were supplied and randomly stocked into 12 fiberglass tanks $200 \mathrm{~L}$ ( 20 fish per tank) assigned to four treatments and triplicates. The study was performed in a completely randomized design. The treatments were feeding carps with experimental diets containing different levels $(0.0$ [control], $0.5,1$ and $2 \%$ ) of SA. The skin mucus total immunoglobulin and total protein levels in fish fed $2 \%$ SA showed significant increase compared to the control group $(\mathrm{P}<0.05)$. Results showed a significant increase in the GH gene expression in 1 and $2 \%$ SA treatments $(P<0.05)$. The carps fed the diet with $2 \%$ SA showed a significant increase in IGF-1 expression $(\mathrm{P}<0.05)$. The expression of GSTa, and GPX (antioxidant genes) revealed a significant increase in the GSTa (fish fed SA at $1 \%$ and $2 \%$ levels) and GPX gene expression with fish fed $2 \% \mathrm{SA}(\mathrm{P}<0.05)$. Supplementation of fish diet with SA induced a slight elevation in the intestine of all immune-related genes (TNF- $\alpha$, IL-1ß, IL8 and Lyz) compared to the control group ( $P>0.05)$. However, Lyz gene was significantly up-regulated in 1 or $2 \%$ SA treatments. These results confirmed beneficial effects of SA as a feed additive in common carp culture.
\end{abstract}

Key words: common carp, skin mucus, antioxidant defence, immunity, gene expression

\footnotetext{
*Source of financial support: The research project was funded by GUASNR.
} 
Abbreviations used: SCFAs: short chain fatty acids; SA: sodium acetate; GH: growth hormone; IGF1: insulin-like growth factor; GST-a: glutathione S-transferase alpha; Gpx: glutathione peroxidase; IL-1: interleukin-1; IL-8: interleukin-8; IL-10: interleukin-10; Tnf-alpha: tumor necrosis factor; Lyz: lysozyme.

Over the past decades there were extensive research attempts regarding determination of the mode of action of prebiotics on fish health and performance (Nawaz et al., 2018). One of the proposed mechanisms of prebiotics effects on fish immune response is production of short chain fatty acids (SCFA) in fish intestine (Hoseinifar et al., 2017 b). It has been reported that fermentation of prebiotics by probiotics will result in production of SCFA including acetate, propionate, and butyrate that showed numerous beneficial responses on mammalian metabolism (Corrêa-Oliveira et al., 2016). SCFAs known as saturated aliphatic organic acids are composed of one to six carbons named as acetate (C2), propionate (C3), and butyrate (C4) (Cook and Sellin, 1998). Previous studies revealed that dietary administration of SCFAs can cause beneficial effects on animals and human physiological parameters (Corrêa-Oliveira et al., 2016; Canfora et al., 2015; Sanford et al., 2016). In addition, the production of SCFAs after intestinal microbial fermentation involves the immunomodulatory effects of prebiotics (Hoseinifar et al., 2017 a).

The review of literature on administration of SA in aquaculture revealed limited information compared to other SCFAs. The effective roles of $1 \mathrm{~g} \mathrm{~kg}^{-1}$ sodium acetate as additive promoting the growth performances of Arctic charr, Salvelinus alpinus (Ringø, 1992), were reported.

In addition, dietary administration of sodium propionate improved the antioxidant and immune related genes in zebrafish (Safari et al., 2016; Hoseinifar et al., 2017 a). However, to the best of our knowledge, there is little information about possible effects of SA on skin mucus immune responses as well as regulation of genes related to growth, antioxidant defence and immunity. Thus, the present study evaluated the possible effects of SA on modulation of skin mucus immune parameters as well as expression of growth-associated genes (GH, IGF1-1) as well as immunity and antioxidant defence associated genes in intestine of common carp.

\section{Material and methods}

\section{Statement of animal rights}

The study was performed based on the established framework of "ethics in animal researches" suggested by the Ministry of Sciences, Research and Technology and approved by research affairs of Gorgan University of Agricultural Sciences and Natural Resources.

\section{Feeding trial}

The present study was conducted at Gorgan University of Agricultural Sciences and Natural Resources (Golestan Province, Gorgan, Iran). Two hundred and forty 
healthy common carp (mean weight $=15 \pm 0.9 \mathrm{~g}$ ) were purchased from a local farm (Gorgan, Iran). Fish were transported to Aquaculture Lab of the Department of Fisheries and stocked in four 500-L tanks. Prior to the start of experiment, carps were adapted to experimental conditions for two week. During this period, fish were fed with basal diet (Table 1), three times a day. Then, fish $(13.40 \pm 1.10)$ were randomly divided into 12 fiberglass tanks $200 \mathrm{~L}$ (20 fish per tank) assigned to 4 treatments and triplicates. The study was performed in a completely randomized design. Basal diet was formulated as mentioned in Table 1 and supplemented with various levels of SA (Sigma, UK) (0.0 [Control], 0.5, 1 and 2\%) as experimental diets. The experimental diets were kept at $4{ }^{\circ} \mathrm{C}$ until use. Fish were fed to apparent satiation with experimental diets twice a day for 8 weeks. Utmost care was done to avoid feed loses. Tanks were cleaned and siphoned daily and $50 \%$ of water was changed. Water dissolved oxygen, temperature and $\mathrm{pH}$ were controlled daily and kept at $7.2 \pm 0.2 \mathrm{mg} \mathrm{L}^{-1}, 25 \pm$ $0.6^{\circ} \mathrm{C}$, and $7.1 \pm 0.1$, respectively.

Table 1. Dietary formulation and proximate composition of the basal diet (\%)

\begin{tabular}{lc}
\hline & Ingredients \\
\hline Fish meal & 40.0 \\
Wheat flour & 21.0 \\
Soybean meal & 13.5 \\
Gluten & 5.5 \\
Soybean oil & 6.0 \\
Fish oil & 6.0 \\
Mineral premix* & 3.0 \\
Vitamin premix * & 2.0 \\
Binder $\dagger$ & 2.0 \\
Antifungal $\ddagger$ & 0.5 \\
Antioxidant $§$ & 0.5 \\
\hline
\end{tabular}

Proximate composition

(\% dry matter basis)

\begin{tabular}{lr}
\hline Dry matter & 92.22 \\
Crude protein & 36.70 \\
Crude lipid & 11.13 \\
Ash & 3.48
\end{tabular}

\footnotetext{
* Premix detailed by Hoseinifar et al. (2015).

$\uparrow$ Amet binder TM, Mehr Taban-e-Yazd, Iran.

\$ ToxiBan antifungal (Vet-A-Mix, Shenan-doah, IA).

$\S$ Butylated hydroxytoluene (BHT) (Merck, Germany).
}

\section{Determination of immunological parameters in skin mucus}

Skin mucus collection

For evaluation of immunological parameters in skin mucus, feeding was stopped for $24 \mathrm{~h}$. Then, nine fish from each treatment (three fish per replicate) were randomly 
sampled and anaesthetized by using clove powder $\left(500 \mathrm{mg} \mathrm{L}^{-1}\right)$. All experiment was done based on the local ethical guidelines. Fish were transferred to polyethylene bags containing $10 \mathrm{ml}$ of $50 \mathrm{mM} \mathrm{NaCl}$. After 1 min gentle shaking, fish were removed and collected mucus samples were immediately transferred to $15 \mathrm{ml}$ sterile centrifuge tubes, centrifuged and the supernatants were stored until further analysis.

Determination of total protein levels in skin mucus

Skin mucus total protein contents were evaluated by commercial kits (Pars Azmon Co, Tehran, Iran) according to the manufactures' protocol.

Determination of skin mucus total immunoglobulins level

The protocol suggested by Siwicki and Anderson (1993) was followed to determine total protein levels. Briefly, the total protein content of samples was determined as mentioned above. The immunoglobulin molecules were precipitated down by a $12 \%$ polyethylene glycol solution (Sigma, UK). Then, the total protein content was measured again. The difference in protein levels was evaluated as the total Ig levels of skin mucus.

Determination of skin mucus alkaline phosphatase (ALP) levels

Skin mucus enzymes ALP was measured using a commercially available kit (Pars Azmoon, Tehran) and absorbance was read at $405 \mathrm{~nm}$ in a spectrophotometer (Sanchooli et al., 2012).

\section{Gene expression studies}

Sampling

Nine fish were randomly sampled from each treatment, anaesthetized and their liver, brain and intestine were collected as described elsewhere (Safari et al., 2017) and immediately kept at $-80^{\circ} \mathrm{C}$.

Primer design

The primers for GH, IGF-I, GPx, GST-a and IL-1, IL-8, TNF-alpha genes were designed based on sequences available in GenBank (Table 2). An internal control gene, b-actin, was applied to normalize the target genes expression.

Table 2. Used primers sequences and amplification efficiencies for evaluation of growth, antioxidant and immune-associated genes

\begin{tabular}{|c|c|c|c|}
\hline Gene name* & Sequences of primers & Accession no & Efficiency \\
\hline 1 & 2 & 3 & 4 \\
\hline \multirow[t]{2}{*}{ b-Actin } & Forward: AGACATCAGGGTGTCATGGTTGGT & M24113.1 & $97 \%$ \\
\hline & Reverse: CTCAAACATGATCTGTGTCAT & & \\
\hline \multirow[t]{2}{*}{ IL1B } & Forward: ACCAGCTGGATTTGTCAGAAG & AB010701.1 & $98 \%$ \\
\hline & Reverse: ACATACTGAATTGAACTTTG & & \\
\hline \multirow[t]{2}{*}{ IL-8 } & Forward: GTCTTAGAGGACTGGGTGTA & AB470924.1 & $98 \%$ \\
\hline & Reverse: ACAGTGTGAGCTTGGAGGGA & & \\
\hline \multirow[t]{2}{*}{ TNF-alpha } & Forward: GGTGATGGTGTCGAGGAGGAA & AJ311800.1 & $97 \%$ \\
\hline & Reverse: TGGAAAGACACCTGGCTGTA & & \\
\hline
\end{tabular}


Table 2 - contd.

\begin{tabular}{lll|c}
\hline \multicolumn{1}{c}{1} & \multicolumn{1}{c|}{2} & 3 & 4 \\
\hline LYZ & Forward: GTGTCTGATGTGGCTGTGCT & AB027305.1 & $98 \%$ \\
& Reverse: TTCCCCAGGTATCCCATGAT & & \\
GSTA & $\begin{array}{l}\text { Forward: TACAATACTTTCACGCTTTCCC } \\
\text { Reverse: GGCTCAACACCTCCTTCAC }\end{array}$ & DQ411314.1 & $97 \%$ \\
& Forward: AGGAGAATGCCAAGAATG & GQ376155.1 & \multirow{2}{*}{$98 \%$} \\
& Reverse: GGGAGACAAGCACAAGG & & \\
GH & Forward: TCTTCGCATCTCTTTTCACC & M27000.1 & $99 \%$ \\
& Reverse: AGTCGGCCAGCTTCTCA & & \\
IGF1 & Forward: GGCATTGGTGTGATGTCTTT & KP661168.1 & $96 \%$ \\
& Reverse: CATATCCTGTCGGTTTGCTG & & \\
\hline
\end{tabular}

* b-Actin: beta Actin; IL1B: Interleukin 1 beta; IL-8: Interleukin 8; TNF-alpha: Tumor necrosis factor alpha; LYZ: Lysozyme; GSTA: Glutathione S-transferase; GPX: Glutathione peroxidase; GH: Growth hormone; IGF1: Insulin-like growth factor 1 .

\section{RNA isolation and real-time PCR (RT-PCR)}

The samples were routinely analyzed by real-time PCR (RT-PCR) to evaluate gene expression in the liver, brain and intestine of 24-h fasted carps. Total RNA isolation was done by BIOZOL Reagent instructions (Bioflux-Bioer, China) according to manufacturer protocol. The integrity of RNA was examined by $1.5 \%$ agarose gel. Also the concentration of RNA was checked via reading at 260/280 nm by the Nanodrop Spectrophotometer (Wilmington, DE, USA). Thereafter, total RNA was transcribed into cDNA by the cDNA synthesis kit (Invitrogen, Carlsbad, CA, USA) according to the manufacturer's protocol with Applied Biosystems real-time instrument (Applied Biosystems, Foster City, CA, USA) and an oligo-dT primer. Realtime PCR test was done by Fermentase Maxima SYBR Green qPCR Master Mix (1x). The average of three biological replicates was used to reveal the changes in gene regulation. The fold changes in the relative mRNA expression of related genes were measured by the $2^{-\Delta \Delta C t}$ approaches (Livak and Schmittgen, 2001).

\section{Statistical analysis}

Prior to statistical analysis, normality and homogeneity of variance were checked and confirmed. All statistical analyses were conducted using SPSS statistical package version 17.0 (SPSS Inc., Chicago, IL, USA). Data were subjected to a one-way ANOVA test and mean values were considered significantly different at $\mathrm{P}<0.05$. When the differences were significant, Duncan's multiple range test was performed.

\section{Results}

\section{Skin mucus immune parameters}

The effects of different concentrations of SA: $0 \%$ (control), $0.5 \%, 1 \%$ and $2 \%$ on skin mucus immune parameters have been presented in Figures 1, 2 and 3. The 
results revealed remarkable $(\mathrm{P}<0.05)$ increase of skin mucus ALP contents (Table 3 ) in carps fed $0.5 \%, 1 \%$ and $2 \%$ during 56 days compared to control fed fish $(\mathrm{P}<0.05)$. Skin mucus total immunoglobulin and total protein levels in fish fed $2 \%$ SA significantly increased compared to those in control group (Table 3). However, dietary application of SA had no notable effects on ALP activity $(\mathrm{P}>0.05)$. Feeding of diets supplemented with $2 \%$ SA significantly increased skin mucus total immunoglobulin (Table 3) and total protein levels (Table 2) in comparison with those of control group.
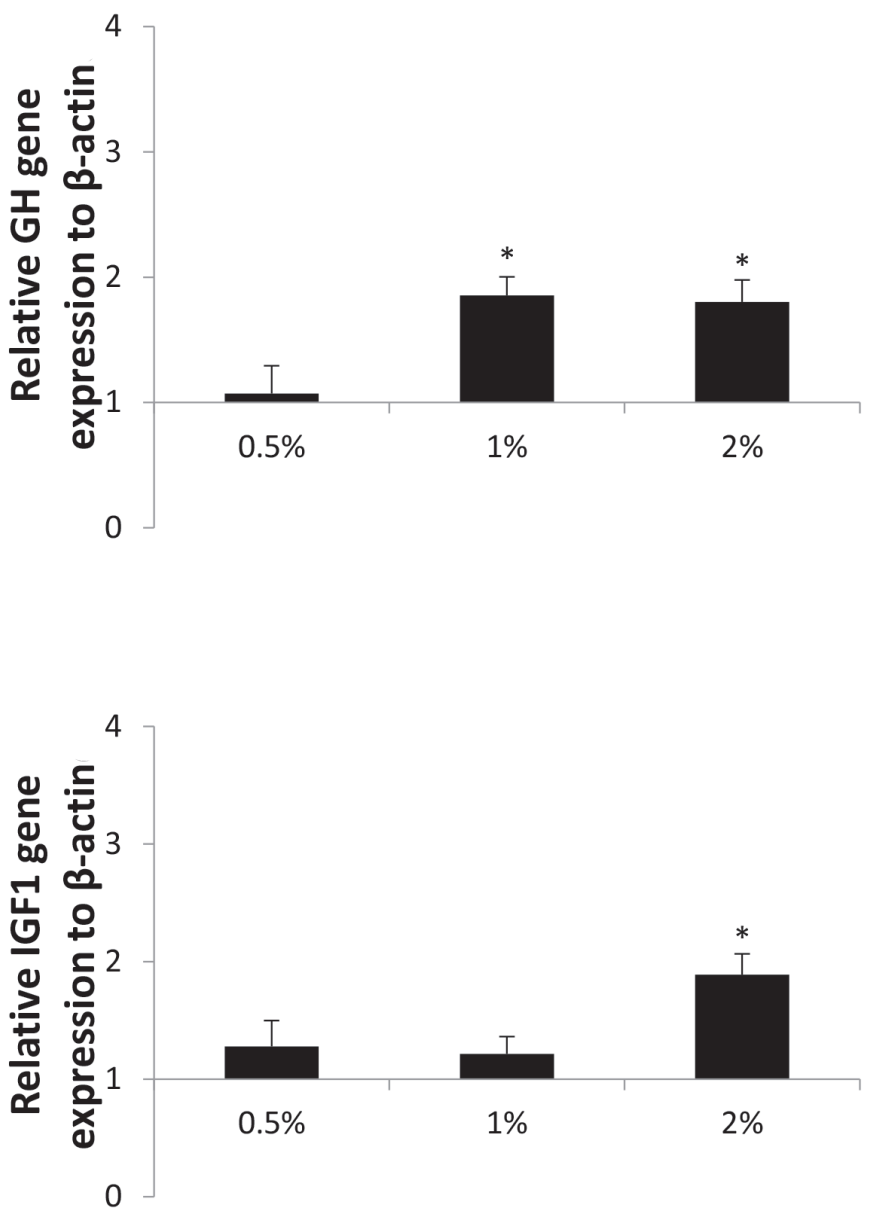

Figure 1. The effects of dietary administration of sodium acetate on the relative expression of GH gene in the brain and IGF1 gene in liver of common carp (Cyprinus carpio) fingerlings. Values are presented as the mean \pm S.D. The bars assigned with asterisk denote significant difference $(\mathrm{P}<0.05)$ 

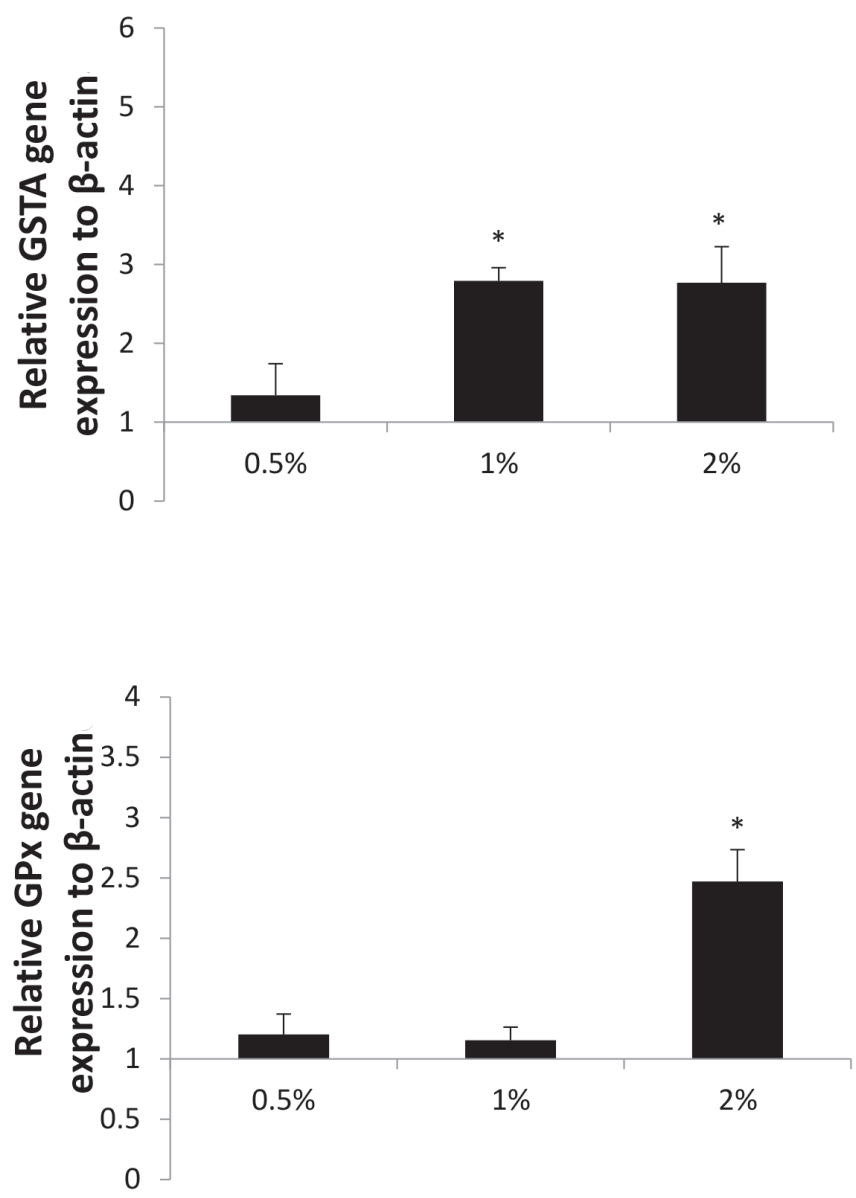

Figure 2. The effects of dietary administration of sodium acetate on the relative expression of antioxidant enzymes genes (GSTA and Gpx) in the intestine of common carp (Cyprinus carpio) fingerlings. Values are presented as the mean \pm S.D. The bars assigned with asterisk denote significant difference

$$
(\mathrm{P}<0.05)
$$

Table 3. Skin mucus immune parameters of common carp (Cyprinus carpio) fingerlings after 8 weeks feeding on experimental diets supplemented with different levels of sodium acetate. Values are presented as the mean \pm S.D.

\begin{tabular}{|c|c|c|c|c|}
\hline & \multicolumn{4}{|c|}{ Experimental treatments } \\
\hline & Control & $0.5 \%$ & $1 \%$ & $2 \%$ \\
\hline Total protein $\left(\mathrm{mg} \mathrm{ml}^{-1}\right)$ & $3.50 \pm 0.15 \mathrm{~b}$ & $4.08 \pm 0.37 \mathrm{~b}$ & $3.63 \pm 0.38 \mathrm{~b}$ & $4.53 \pm 0.21 \mathrm{a}$ \\
\hline Total Ig $\left(\mathrm{mg} \mathrm{ml}^{-1}\right)$ & $1.82 \pm 0.14 \mathrm{~b}$ & $2.17 \pm 0.18 \mathrm{~b}$ & $2.04 \pm 0.09 \mathrm{~b}$ & $2.90 \pm 0.34 \mathrm{a}$ \\
\hline ALP activity ( $\mathrm{U} \mathrm{ml}^{-1}$ ) & $433.5 \pm 33.1 \mathrm{~b}$ & $481.7 \pm 16.4 \mathrm{a}$ & $491.7 \pm 8.7 \mathrm{a}$ & $512.6 \pm 12.4 \mathrm{a}$ \\
\hline
\end{tabular}

The same letter in each row means non-significant difference $(\mathrm{P}>0.05)$. 

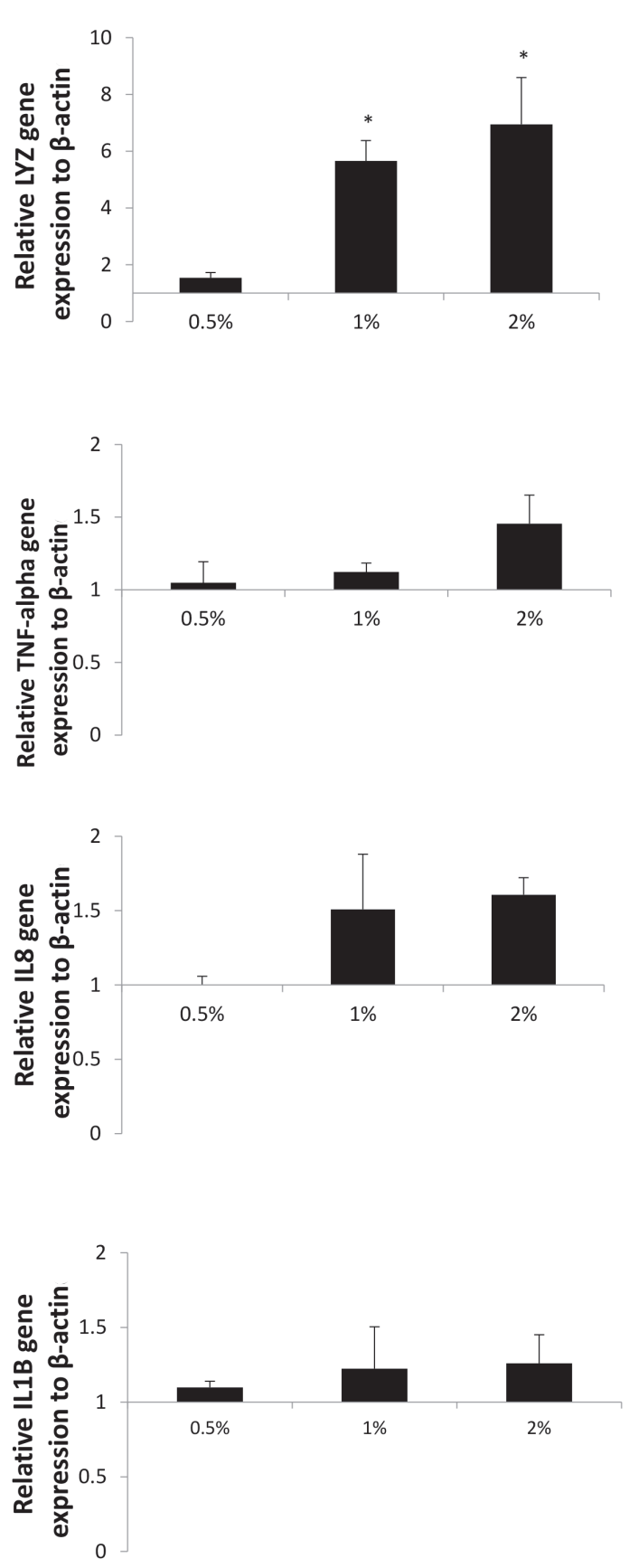

Figure 3. The effects of dietary administration of sodium acetate on the relative expression of immune related (Lyz, TNF- $\alpha$, IL8 and IL-1 $\beta$ ) in the intestine of common carp (Cyprinus carpio) fingerlings. Values are presented as the mean \pm S.D. The bars assigned with asterisk denote significant difference $(\mathrm{P}<0.05)$ 


\section{Growth related genes expression}

The expression of key growth-associated genes after 56 days treatment of carps with 5, 10 and $20 \mathrm{~g} \mathrm{~kg}^{-1}(0.5 \%, 1 \%$ and $2 \%$, respectively) SA are shown in Figure 1. Our results showed a notable up-regulation of GH gene in fish fed 1 and $2 \%$ $\mathrm{SA}$ compared to control $(\mathrm{P}<0.05)$. There was no significant difference between $0.5 \%$ SA and control. However, the expression of IGF-1 gene revealed a slight increase in SA of fish fed with $0.5 \%, 1 \%$ that was not statistically significant compared to that of fish fed control diet $(\mathrm{P}>0.05)$. On the other hand, evaluation of IGF-1 expression revealed notable up-regulation following feeding with $2 \% \mathrm{SA}(\mathrm{P}<0.05)$.

\section{Antioxidant related genes expression}

GSTa was significantly up-regulated in fish fed 1\% and 2\% SA (Figure 2). Also, GPX gene expression was notably increased in fish fed $2 \%(\mathrm{P}<0.05)$, whereas no significant increases were shown in liver from fish fed SA enriched diet with $0.5 \%$ in GSTa gene expression and $0.5 \%$ and $1 \%$ in GPX gene expression, compared to control group $(\mathrm{P}>0.05)$.

\section{Immune related genes expression}

The results of immune-associated genes expression revealed slight elevation in the expression of all immune-related genes (TNF- $\alpha$, IL-1 $\beta$, IL8) $(\mathrm{P}>0.05)$ compared to the control group (Figure 3), while feeding with 1 or $2 \%$ SA resulted in significant up-regulation of Lyz gene $(\mathrm{P}<0.05)$.

\section{Discussion}

This study was performed to determine if dietary SA can improve growth, immunity and antioxidant defence in common carp. The results revealed a remarkable elevation in the growth-associated gene $(\mathrm{GH})$ expression in fish fed 1 and $2 \% \mathrm{SA}$. Also, a slight increase was noticed in the expression of IGF-1 in $0.5 \%$ and $1 \% \mathrm{SA}$ groups and a notable increase was observed in $2 \%$ SA treatment. Similar results were reported in another study regarding the effects of dietary sodium propionate (SP) on zebrafish (Hoseinifar et al., 2017 a). In contrast with the present results, Katoh et al. (1999) found SCFAs such as butyrate and propionate suppressed anterior pituitary cells of goats through the GH-releasing hormone. To the best of our knowledge, there is no available study on possible effects of SA on GH gene expression. However, in agreement with our results, feeding with SP supplemented diet improved growth performance of Caspian white fish (Rutilus frisii kutum) (Hoseinifar et al., 2016). In addition, significant increase of growth rate, phosphorus availabilities, feed intake and apparent gross energy were observed in shrimp (Litopenaeus vannamei) fed SP (da Silva et al., 2013; da Silva et al., 2016). It has been suggested that the improvement of growth performance following feeding with SCFAs could be due to increase of digestive function as well as improved intestinal morphology ( $\mathrm{Ng}$ and Koh, 2017). In agreement, SCFAs were reported to regulate epithelial function through elevation 
of $\mathrm{Na}+/ \mathrm{H}+$ exchange and the expression of proteins in the apical membranes (Musch et al., 2001).

Moreover, the present study showed significant increase of antioxidant defence related genes (GSTa and GPX) expression in common carps fed SA diets. Accordingly, it has been reported that sodium acetate could play an antioxidant role and delay lipid oxidation in refrigerated sliced salmon and rainbow trout (Sallam, 2007; Haghparast et al., 2010). Although the positive changes in the activities of antioxidant enzymes genes expression could reveal beneficial effects of SA on antioxidant system, additional studies regarding analysis of antioxidant enzymes activity are needed to confirm this. In the present study, it was not possible to measure the activity of antioxidant enzymes and just based on gene expression results it cannot be concluded that SA has positive effects on antioxidant defence.

The study of immune-related genes (TNf- $\alpha$, IL-1 $\beta$, IL8) expression in common carp intestine following dietary administration of SA revealed a slight increase while in case of Lyz gene expression significant up-regulation was noticed in 1 or $2 \% \mathrm{SA}$ treatments. Also, significant increase was noticed in case of non-specific immune parameters (total Ig, total protein and alkaline phosphatase) in skin mucus of carps fed SA. There is limited data about immunomodulatory effects on SCFAs (Ng and Koh, 2017; Cook and Sellin, 1998). However, in agreement with present results, SP was capable of increasing mucosal immune parameters of Caspian white fish fry and zebrafish (Hoseinifar et al., 2016; Hoseinifar et al., 2017 c; Safari et al., 2016). Also, Reda et al. (2016) reported a notable increase of immune parameters such as lysozyme activities, serum bactericidal index and nitric oxide in Nile tilapia fed propionic acid. Moreover, it is well reported that impairment of SCFAs production could induce inflammatory bowel disease (IBD) (Vinolo et al., 2011; Thibault et al., 2010). Furthermore, it has been reported that SCFAs play important roles in the maintenance of integrity of the mucosal barrier, which per se could result in modulation of mucosal immune parameters.

In conclusion, the present study demonstrated that oral administration of SA upregulates growth, immune and antioxidant related genes as well as improves skin mucus immune responses. Our finding in this study proposes dietary administration of SA as beneficial feed additive in common carp fingerlings culture.

\section{Conflict of interest statement}

There is no conflict of interest to declare.

\section{Acknowledgements}

This research work was partially supported by Chiang Mai University.

\section{References}

C a n for a E.E., J o c k e n J.W., B l a a k E.E. (2015). Short-chain fatty acids in control of body weight and insulin sensitivity. Nat. Rev. Endocrinol., 11: 577.

C o o k S., S e 11 in J. (1998). Short chain fatty acids in health and disease. Alim. Pharmacol. Therap., 12: 499-507. 
Corrêa-Oliveira R., F a ch i J.L., Vie ir a A., S a to F.T., Vin olo M.A.R. (2016). Regulation of immune cell function by short-chain fatty acids. Clin. Translat. Immunol., 5: e73.

da Silva B.C., do Nascimento Vieira F., Mouriño J.L.P., Ferreira G.S., Seiffer t W.Q. (2013). Salts of organic acids selection by multiple characteristics for marine shrimp nutrition. Aquaculture, 384:104-110.

d a Silva B.C., Vie ir a F.d.N., Mouriñ o J.L.P., B ol ivar N., S e iffert W.Q. (2016). Butyrate and propionate improve the growth performance of Litopenaeus vannamei. Aquacult. Res., 47: $612-623$.

Hagh parast S., Ka shiri H., Shab a n pour B., Pahlavani M. (2010). Antioxidant properties of sodium acetate, sodium citrate and sodium lactate on lipid oxidation in rainbow trout (Onchorhynchus mykiss) sticks during refrigerated storage $\left(4^{\circ} \mathrm{C}\right)$. Iran. J. Fisheries Sci., 9: 73-86.

H o s e in i far S.H., Z o h e i r i F., C a i p a n g C.M. (2016). Dietary sodium propionate improved performance, mucosal and humoral immune responses in Caspian white fish (Rutilus frisii kutum) fry. Fish and Shellfish Immunol., 55: 523-528.

Ho s e in if ar S.H., S a fari R., Dad a r M. (2017 a). Dietary sodium propionate affects mucosal immune parameters, growth and appetite related genes expression: Insights from zebrafish model. Gen. Comp. Endocrinol., 243: 78-83.

Ho s e in if a r S.H., S u n Y.-Z., Ca i p a n g C.M. (2017 b). Short chain fatty acids as feed supplements for sustainable aquaculture: an updated view. Aquacult. Res., 48: 1380-1391.

Hos e in ifar S.H., Zou H.K., Miandare H.K., Van Doan H., Romano N., Dadar M. (2017 c). Enrichment of common carp (Cyprinus carpio) diet with medlar (Mespilus germanica) leaf extract: effects on skin mucosal immunity and growth performance. Fish and Shellfish Immunol., 67: 346-352.

K a t o h K., O h a t a Y., I s h iw a t a H. (1999). Suppressing effects of short-chain fatty acids on growth hormone $(\mathrm{GH})$-releasing hormone-induced $\mathrm{GH}$ release in isolated anterior pituitary cells of goats. Dom. Anim. Endocrinol., 17: 85-93.

Livak K.J., S chmittgen T.D. (2001). Analysis of relative gene expression data using real-time quantitative PCR and the 2- $\Delta \Delta \mathrm{CT}$ method. Meth., 25: 402-408.

Musch M.W., B ookstein C., Xi e Y., Sellin J.H., Chang E.B. (2001). SCFA increase intestinal $\mathrm{Na}$ absorption by induction of NHE3 in rat colon and human intestinal C2/bbe cells. Am. J. Physiol. Gastrointes. Liver Physiol., 280: G687-G693.

Naw a z A., B a khsh javaid A., Irshad S., Ho s e in ifar S.H., Xiong H. (2018). The functionality of prebiotics as immunostimulant: Evidences from trials on terrestrial and aquatic animals. Fish and Shellfish Immunol., 76: 272-278.

$\mathrm{N} g$ W.K., K o h C.B. (2017). The utilization and mode of action of organic acids in the feeds of cultured aquatic animals. Rev. Aquacul., 9: 342-368.

R e d a R.M., M a h m o u d R., S e 1 i m K.M., E 1 - A r a b y I.E. (2016). Effects of dietary acidifiers on growth, hematology, immune response and disease resistance of Nile tilapia, Oreochromis niloticus. Fish and Shellfish Immunol., 50: 255-262.

R in gø E. (1992). Effects of dietary formate and acetate on growth and lipid digestibility in Arctic charr, Salvelinus alpinus (L.). Fiskeridirektoratets Skrifter Serie Ernæring, 5: 17-24.

$\mathrm{S}$ a fari R., Hos e in if a r S.H., K a vand i M. (2016). Modulation of antioxidant defense and immune response in zebra fish (Danio rerio) using dietary sodium propionate. Fish Physiol. Biochem., 42: $1733-1739$.

S a fari R., Hos e in if a r S.H., Van D o a n H., D a d a r M. (2017). The effects of dietary Myrtle (Myrtus communis) on skin mucus immune parameters and mRNA levels of growth, antioxidant and immune related genes in zebrafish (Danio rerio). Fish and Shellfish Immunol., 66: 264-269.

S a 11 a m K.I. (2007). Antimicrobial and antioxidant effects of sodium acetate, sodium lactate, and sodium citrate in refrigerated sliced salmon. Food Cont., 18: 566-575.

S a n chooli O., Haji moradloo A., Ghorbani R. (2012). Measurement of alkaline phosphatase and lysozyme enzymes in epidermal mucus of different weights of Cyprinus carpio. World J. Fish Mar. Sci., 4: 521-524.

S a n ford J.A., Zhang L.-J., Willi a m s M.R., Gango it i J.A., H u ang C.-M., Gallo R.L. (2016). Inhibition of HDAC8 and HDAC9 by microbial short-chain fatty acids breaks immune tolerance of the epidermis to TLR ligands. Sci. Immunol., 1: eaah4609. 
S i w i c k i A.K., A n d e r s o n D.P. (1993). Nonspecific defense mechanisms assay in fish: II. Potential killing activity of neutrophils and macrophages, lysozyme activity in serum and organs and total immunoglobulin level in serum. Fish Disease Diagnosis and Prevention Methods. Olsztyn, Poland, pp. $105-112$.

Thibault R., Blachier F., Darcy-Vrillon B., De Coppet P., Bourreille A., Sega in J.P. (2010). Butyrate utilization by the colonic mucosa in inflammatory bowel diseases: a transport deficiency. Inflammat. Bowel Dis., 16: 684-695.

Vin olo M.A., Rodrigues H.G., N a chbar R.T., Curi R. (2011). Regulation of inflammation by short chain fatty acids. Nutri., 3: 858-876.

Received: 10 XII 2019

Accepted: 5 V 2020 